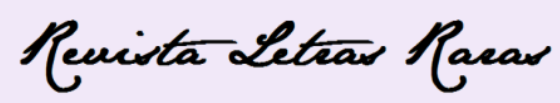

ISSN: 2317-2347 - Vol. 5, Ano 5, № 1 - 2016

\title{
Educação bilíngue de surdos: uma proposta de implementação na rede municipal de educação de Juiz de Fora/ MG
}

\author{
Ana Paula Xavier (Mestranda - CMPDI) ${ }^{1 *}$ \\ Gabriel Pigozzo Tanus Cherp Martins (Mestrando - CMPDI)* \\ Cláudia Mara Lara Melo Coutinho (PhD - CMPDI)* \\ Ruth Maria Mariani $\left(\mathrm{Dr}^{\mathrm{a}}-\mathrm{CMPDI}\right)^{*}$
}

\begin{abstract}
Resumo: A educação de Surdos vem sofrendo significativos avanços no que se refere às políticas públicas que, invariavelmente, desaguam dentro dos ambientes escolares. Pensar em uma educação que atenda as especificidades linguísticas destes sujeitos é imperioso no atual momento. O presente artigo tem como objetivo apresentar como se deu a implementação de uma proposta inclusiva bilíngue para Surdos em uma escola comum e os caminhos percorridos para tal. As escolas bilíngues, também chamadas escolas de Surdos, são aquelas em que a língua de instrução é a Língua Brasileira de Sinais (LIBRAS). Nos ancoramos nos estudos de Albres (2015) e Pereira (2011) para fundamentar o conceito de bilinguismo e em Lacerda e Lodi (2010) e Alves, Pereira e Damázio (2010) encontramos os fundamentos que alicerçam a importância do Ensino Bilíngue na construção da equidade nos processos de aprendizagem dos sujeitos surdos, além da legislação vigente. Diante das inquietações e na busca de possibilitar ao aluno Surdo melhores condições de aprendizagem e de fomentar sua autonomia linguística implementamos, em conjunto com profissionais que trabalhavam no Núcleo de Atendimento a Criança em Idade Escolar Sul (NEACE/Sul), uma proposta "nova" e diferenciada na rede municipal de ensino: Uma proposta de Ensino Inclusivo Bilíngue. Faremos uma breve análise dos documentos oficiais que norteiam as políticas públicas de educação de Surdos bem como os processos de inclusão destas políticas no âmbito escolar. Assumimos aqui o papel na gestão e tendo este olhar como base fundamental para a promoção de uma educação mais equânime e com qualidade para os sujeitos Surdos entendendo que as grandes dificuldades de substancializar uma política mais efetiva estão alojadas em barreiras filosóficas, políticas e também pedagógicas. Para entendermos a necessidade e importância desta perspectiva para a aprendizagem dos alunos Surdos, precisamos compreender o que é Bilinguismo e o que significa o BI em bilinguismo e como assegurar o ensino de sua língua natural LIBRAS (L1) dando centralidade e retirando do nosso entendimento o estereótipo de deficiente do sujeito Surdo.
\end{abstract}

Palavras-Chave: Educação bilíngue para Surdos, bilinguismo, estratégias de ensino para surdos.

\section{BILINGUAL EDUCATION FOR DEAF PEOPLE: AN IMPLEMENTATION PROPOSAL IN THE MUNICIPAL NETWORK OF JUIZ DE FORA/MG}

\footnotetext{
Abstract: The deaf education has undergone significant advances with regard to public policies invariably flow into within school environments. Think of an education that meets the linguistic specificity of these subjects is imperative nowadays. This article aims to present how was the implementation of a bilingual inclusive proposal for the Deaf People in a regular school and the paths taken to do so. The bilingual schools, also called deaf schools are those where the language of instruction is the Brazilian Sign Language (Libras). In anchored in studies Albres (2015) and Pereira ( 2011) to support the concept of bilingualism and Lacerda and Lodi (2010) and Alves, Pereira and Damázio (2010) found the fundamentals that underpin the importance of Bilingual Education in Construction equity in the learning process of deaf people, in addition to the current legislation. Faced with the concerns and

${ }^{*}$ Professora no CAEE/Centro na cidade de Juiz de Fora e mestranda no Curso Diversidade e Inclusão - UFF.

Contato: anapaulaxavier74@mail.com

* Intérprete de LIBRAS no CAEE/Centro e professor de L2 no CAEE/Sul e mestrando no Curso Diversidade e Inclusão - UFF. Contato: tanuscherp84@gmail.com.

* claudialaramelocoutinho@gmail.com.

* ruthmariani@ig.com.br.
} 


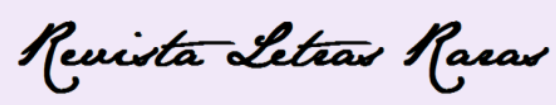

ISSN: 2317-2347 - Vol. 5, Ano 5, № 1 - 2016

seeking to enable deaf student best learning conditions and foster their linguistic autonomy, we implemented in conjunction with working at the South Center for Assistance to Children at School (Neace / South), a "new" and differentiated proposal in the public schools : a proposal for Inclusive education Bilingual. We will make a brief analysis of the official documents that guide public policies for Deaf education and the processes of inclusion of these policies in schools. We assume here the role in the management and the latter look as a fundamental basis for promoting a more equitable education and quality for Deaf People understanding that the major difficulties to accomplish a more effective policy are housed in philosophical barriers, political and also educational. To understand the necessity and importance of this development for the learning of Deaf students, we must understand what Bilingualism is and what it means BI in bilingualism and how to ensure the education of their natural language Libras (L1) providing centrality and removing from our understanding the poor deaf guy stereotype.

Key words: Bilingual education for Deaf People. Bilingualism. Teaching strategies for the deaf students.

\section{INTRODUÇÃO}

A educação de Surdos vem sofrendo significativos avanços no que se refere às políticas públicas que, invariavelmente, desaguam dentro dos ambientes escolares. Pensar em uma educação que atenda as especificidades linguísticas destes sujeitos é imperioso no atual momento. As grandes dificuldades de efetivação de uma política mais efetiva estão alojadas em barreiras filosóficas, políticas e também pedagógicas.

Desde 2002 com a promulgação da Lei 10.436 (Lei de LIBRAS) e com o Decreto 5626, em 2005, que garantiram a LIBRAS como língua natural dos Surdos, muito se tem discutido sobre como garantir acesso e qualidade no ensino aos alunos Surdos. Esse sistema linguístico -LIBRAS- de natureza visual-motora e estrutura gramatical própria é reconhecida como língua oficial no Brasil (BRASIL, 2002) e, com essa oficialização pela Lei Federal, os Surdos passam a ser legalmente reconhecidos como grupo minoritário e cultural (Fernandes e Moreira, 2009).

De acordo com o Decreto acima citado,

Considera-se pessoa surda, aquela que, por ter perda auditiva, compreende e interage com o mundo por meio de experiências visuais, manifestando sua cultura principalmente pelo uso da Língua Brasileira de Sinais - Libras (BRASIL, 2005).

A escola comum ${ }^{2}$ atende as demandas e especificidades linguísticas destes sujeitos? Ou será preciso pensar em outra perspectiva? Uma perspectiva que ofereça um processo de aprendizagem contextualizado, que forneça ao aprendiz Surdo condições de desenvolver suas

\footnotetext{
2 “'Escola comum' consiste da escola laica, gratuita e para todos. Apesar de, por vezes, os termos escola comum e escola regular serem usados indistintamente, optamos por não utilizar o termo escola regular. O termo escola regular carrega o conceito de que a escola especial ou exclusiva para surdos seria uma escola "irregular".
}

(ALBRES, 2015, p. 14-15) 


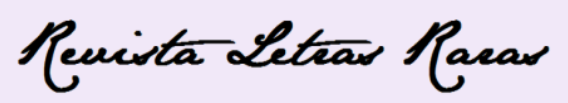

ISSN: 2317-2347 - Vol. 5, Ano 5, № 1 - 2016

habilidades linguísticas, cognitivas e sócio-afetivas. Entendemos que tal perspectiva passa, invariavelmente por uma mudança de olhares, por uma descristalização curricular, por uma desconstrução metodológica, para então, repensarmos e reconstruirmos o processo de educação do sujeito Surdo compreendendo sua natureza linguística e os estilos cognitivos diferentes ${ }^{3}$, pois "à medida que a condição linguística do Surdo é respeitada, aumentam as chances de ele desenvolver-se e construir novos conhecimentos de maneira satisfatória (...)" (LACERDA; LODI, 2010). O desafio de ensinar a todos, independentemente de suas necessidades específicas é um fato que se impõe na atualidade e no seio escolar. O professor tem que pensar, caso a caso, a melhor forma de trabalhar com o aluno, que recursos serão utilizados para que a construção de sua aprendizagem seja levada a termo. Isso se revelará na singularidade de cada sujeito, no estilo de aprender de cada aluno

Diante destas inquietações e na busca de possibilitar ao aluno Surdo melhores condições de aprendizagem e de fomentar sua autonomia linguística implementamos, em conjunto com profissionais que trabalhavam no Núcleo de Atendimento a Criança em Idade Escolar Sul (NEACE/Sul), uma proposta "nova" e diferenciada na rede municipal de ensino: Uma proposta de Ensino Inclusivo Bilíngue (ALBRES, 2015).

O objetivo deste trabalho é apresentar como se deu a implementação de uma proposta de ensino inclusivo bilíngue em uma escola comum da rede municipal da cidade de Juiz de Fora - MG, tendo como referência as demandas de aprendizagem dos alunos Surdos e a importância de uma educação bilíngue para a promoção mais efetiva de possibilidades. Não nos cabe aqui discorrer sobre as políticas públicas que envolvem estes processos. Nosso foco se pautará no olhar da gestão com todas as demandas e entraves que a função traz em si.

É possível pensarmos em uma sociedade onde o olhar não configure em uma “miopia' social que assombra as relações de ensino aprendizagem? É possível pensar em uma proposta que fortaleça e empodere o sujeito Surdo em um de seus espaços primeiro de relações sociais (escola)? Bom, acreditamos e lutamos pela concretude destas ideias. Este é o ponto de partida para este trabalho.

Para entendermos a necessidade e importância desta perspectiva para a aprendizagem dos alunos Surdos, precisamos compreender o que é Bilinguismo e o que

\footnotetext{
${ }^{3}$ O conceito de "estilo cognitivo" usado por Kupfer (1999) define que "um estilo pode ser um modo próprio, único de escrever, de falar, de se posicionar" (p.72). Ou seja, estilo cognitivo pode ser entendido como uma forma única, singular, própria do indivíduo aprender.
} 


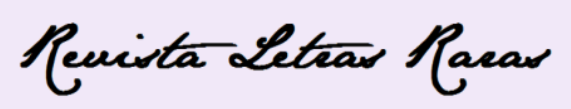

ISSN: 2317-2347 - Vol. 5, Ano 5, № 1 - 2016

significa o BI em bilinguismo. Não nos atentaremos para as outras concepções de ensino para o educando Surdo. Nosso foco será a proposta bilíngue.

\section{CAMINHOS}

As escolas bilíngues, também chamadas escolas de Surdos, são aquelas em que a língua de instrução é a LIBRAS. Mas o que caracteriza o bilínguismo?

O bilinguismo refere-se ao ensino de duas línguas para os Surdos: a primeira, a língua de sinais, dá arcabouço para o aprendizado da segunda, a língua majoritária - preferencialmente na modalidade escrita (PEREIRA et al, 2011, p. 12).

Há um erro recorrente em afirmar que escolas bilíngues, assim se tornam, pelo simples fato de terem instrutores ou intérpretes de LIBRAS em seu quadro profissional, permeando os fazeres escolares. Não é tão simples assim.

Ao pensarmos em uma proposta de ensino inclusivo bilíngue nos deparamos com inúmeros desafios. A concretude destas ações não são tarefa fácil para a gestão de uma escola pública que depende dos meandres políticos que envolvem a educação pública, imbricada nas questões da inclusão.

Para entendermos como implementar uma proposta de ensino inclusivo bilíngue em uma escola comum que atenda as demandas e se paute em uma educação equânime, precisamos compreender qual o espaço mais adequado para que este processo aconteça. Seria realmente a escola bilíngue este espaço? Além de compreendermos o "lugar" que o Surdo ocupa hoje em nossa sociedade.

Inicialmente foi preciso estabelecer uma parceria que fomentasse junto com a escola as necessidades e a importância de oferecer um ensino em que as especificidades linguísticas dos Surdos fossem compreendidas. Para tal era imprescindível compreender o conceito de bilinguismo e em que, esta proposta se diferenciava (e se distanciava) da escola especial, das escolas comuns inclusivas e das escolas especiais para Surdos.

O primeiro passo então, foi buscar este conhecimento junto com os profissionais do NEACE/Sul. Entender o que é cultura surda, identidade surda, educação de Surdos, bilinguismo, conceitos estes que permeiam a educação de Surdos. De início, já era muito a se fazer. 


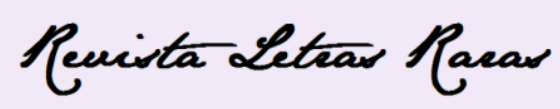

ISSN: 2317-2347 - Vol. 5, Ano 5, № 1 - 2016

De acordo com os documentos oficiais que norteiam as políticas educacionais em nosso país, entende-se que

A Educação Bilíngue de Surdos envolve a criação de ambientes linguísticos para a aquisição da Libras como primeira língua (L1) por crianças surdas, no tempo de desenvolvimento linguístico esperado e similar ao das crianças ouvintes, e a aquisição do português como segunda língua (L2). [...] O objetivo é garantir a aquisição e a aprendizagem das línguas envolvidas como condição necessária à educação do Surdo, construindo sua identidade linguística e cultural em Libras e concluir a educação básica em situação de igualdade com as crianças ouvintes e falantes do português (BRASIL, 2014, p. 6).

Partindo desta premissa buscamos junto a Secretaria Municipal de Educação o apoio para iniciarmos o trabalho. Primeiramente precisávamos de professores Surdos para trabalhar nas turmas onde havia matrícula de aluno Surdo. Este profissional era imprescindível para a constituição identitária deste educando, sendo seu modelo linguístico e cultural. Muitos autores

Advogam a implantação de uma educação bilíngue para Surdos, que defende que estes sujeitos devam interagir com interlocutores usuários de língua de sinais o mais precocemente possível, identificada como uma língua passível de ser desenvolvida sem que sejam necessária condições especiais de "aprendizagem". (LACERDA E LODI, 2010)

Após esta primeira etapa se fazia urgente fomentar no meio escolar a importância do conhecimento e a necessidade da aquisição e difusão da LIBRAS, da identidade e da cultura surda, da legitimidade da comunidade surda como minoria linguística com uso da LIBRAS, pois entendemos que

[...] torna-se urgente repensar a educação escolar dos alunos com surdez, tirando o foco do confronto do uso desta ou daquela língua e buscar redimensionar a discussão acerca do fracasso escolar, situando-a no debate atual acerca da qualidade da educação escolar e das práticas pedagógicas. É preciso construir um campo de comunicação e de interação amplos, possibilitando que a língua de sinais e a língua portuguesa, preferencialmente a escrita, tenham lugares de destaque na escolarização dos alunos com surdez, mas que não sejam o centro de todo o processo educacional (ALVEZ; FERREIRA; DAMÁZIO, 2010, p. 8).

O aluno Surdo, por sua singularidade linguística, confronta a escola quando suas singularidades não são respeitadas. Este se dá através de conflitos estabelecidos cotidianamente 


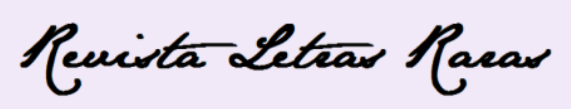

ISSN: 2317-2347 - Vol. 5, Ano 5, № 1 - 2016

entre "mundos" opostos. A falta de reflexão sobre o processo de ensino aprendizagem, por parte dos docentes, é a "ponta" de um iceberg, cuja profundidade não somos capazes de mensurar.

Um discurso muito conhecido no meio docente é: "não estamos preparados para receber este tipo de aluno"; "não estudei LIBRAS durante minha formação". Este tipo de discurso é um dos inúmeros entraves para fortalecer a educação de Surdos. Principalmente à educação inclusiva bilíngue. Para desintegrar esse recorrente discurso implementamos um curso de LIBRAS, ministrado por profissionais Surdos e ouvintes, para iniciar e fomentar as discussões sobre a língua, a cultura, a identidade, a forma de conviver destes sujeitos no ambiente escolar. Este curso visava atender, prioritariamente, os profissionais da escola e também da rede municipal.

Com a chegada dos profissionais Surdos e da criação do curso, foram estabelecidos momentos de estudo, pesquisa e capacitação. Temas como bilinguismo, a legislação que perpassa a educação de Surdos, métodos, estratégias e práticas de ensino, implementação das turmas, foram sendo discutidos neste primeiro ano e ao seu final alterações foram realizadas no Projeto Político Pedagógico da escola de forma a consubstanciar a proposta de tal maneira que a mesma deixasse de pertencer a um ideal de gestão e passasse a ser um ideal de todos.

No ano seguinte (2013), a escola recebe um número considerável de matrículas de alunos Surdos. É chegado um professor Surdo para divulgar a LIBRAS dentro do ambiente escolar e a proposta começa a se consolidar. O resultado deste "boom" de matrículas, nos mostra que a educação inclusiva bilíngue é uma proposta que atende aos anseios educacionais do sujeito Surdo, além de nos colocar de frente a um caminho de novas possibilidades.

Conhecer a importância da LIBRAS para a aquisição do conhecimento e do desenvolvimento do aluno Surdo se fez mister para que solicitássemos junto à Secretaria de Educação (SE), no ano de 2014, um profissional Surdo, para atuar como modelo linguístico, cultural e identitário. Este trabalharia no entre turnos (matutino e vespertino), num contexto de imersão linguística, favorecendo o aprendizado da LIBRAS.

Estes foram os primeiros passos para a implementação da proposta inclusiva bilíngue em uma escola comum, da rede pública municipal. Primeiros passos, sim! Por que? Por que assim como o rio sempre corre para o mar, pensar em propostas que favoreçam a educação de nossas crianças, sejam elas surdas ou não, não pode findar em uma proposta. Não pode ser finita! Deve ser sempre instigada, estimulada, criticada, orientada e ampliada.

\subsection{A ESCOLA}




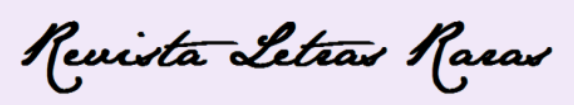

ISSN: 2317-2347 - Vol. 5, Ano 5, № 1 - 2016

Para atender os preceitos de uma educação inclusiva bilíngue, além da dinâmica conceitual, do mergulho no "mundo" Surdo, dos estudos e do entendimento da proposta foram necessárias alterações para que o respeito às especificidades educacionais dos sujeitos Surdos fossem legitimadas dentro do espaço escolar.

Sendo a LIBRAS a língua de instrução dos alunos Surdos e respeitando o direto de acesso aos conhecimentos escolares em sua L1, a escola percebeu a necessidade de organizar as turmas, que possuíam Surdos, com o trabalho de bidocência .

O trabalho de bidocência é realizado por dois professores, um ouvinte e o outro, preferencialmente, Surdo. Não havendo a possibilidade de contratação deste profissional Surdo o trabalho é realizado por um profissional ouvinte com proficiência em LIBRAS. Ambos assumem a responsabilidade pela turma. Isso implica em uma divisão de tarefas como o planejamento em conjunto, os processos de avaliação, distribuição dos conteúdos e registros formais próprios do cotidiano escolar.

Outro aspecto a ser considerado para a promoção da acessibilidade comunicacional foi a sinalização luminosa por toda a escola. Concomitantemente ao toque do sinal sonoro, em todos os espaços da escola, são disparados sinais luminosos, identificando assim, horários de saída, entrada, intervalos e início e término das aulas. Desta forma, possibilitamos autonomia, direito de ir e vir, para os alunos Surdos nos espaços da escola.

\section{RESULTADOS}

Difícil pensar em resultados quando acreditamos, pensamos e agimos em prol de mudanças. Mudanças de concepções, paradigmas e posturas. Mudanças legais, estruturais e conceituais. Pensar educação de Surdos é caminhar em terreno arenoso e se beneficiar das sombras de um maravilhoso coqueiro. É lutar. É olhar para o outro e para si. É partilhar línguas, culturas, identidades. Estar no mesmo espaço usando e compartilhando experiências diferentes. Visual. Oral. Gestual. Educação de Surdos é isso. Um emaranhado de caminhos que se entre cruzam nos entre espaços da educação. Educação de Surdos é educação. E como toda a educação, não pode ser finita! Não pode ser um fim em si mesma. Ela é o meio. O meio de trazer autonomia, equidade, empoderamento do sujeito Surdo.

Este trabalho objetivou discursar sobre a implementação de uma proposta de ensino inclusivo bilíngue em uma escola comum da rede pública de Juiz de Fora. Ao longo desse 


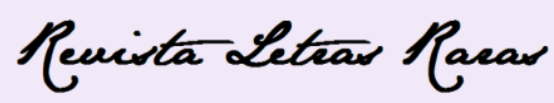

ISSN: 2317-2347 - Vol. 5, Ano 5, № 1 - 2016

caminhar apresentamos as conquistas e dificuldades encontradas para implementação e continuidade da proposta. Pensar em ações cotidianas se ancorando em valores e proposições éticas e solidárias, no aparato legal e nas concepções sócio-culturais, filosóficas e pedagógicas que permeiam o fazer escolar na busca de superar a imanência e romper fronteiras.

\section{REFERÊNCIAS}

ALBRES, N.A. Intérprete Educacional: políticas e práticas em sala de aula inclusiva. São Paulo: Harmonia, 2015.

ALVEZ, C. B.; FERREIRA, J. P.; DAMÁZIO, M. M. A Educação Especial na Perspectiva da Inclusão Escolar. Abordagem Bilíngue na Escolarização de Pessoas com Surdez. Universidade Federal do Ceará. Brasília: MEC/SEESP, 2010.

BRASIL. Relatório do Grupo de Trabalho designado por Portaria Ministerial para elencar subsídios à Política Linguística de Educação Bilíngue - Língua Brasileira de Sinais e Língua Portuguesa. Brasília: MEC/SEESP, 2014.

. Lei de Libras. Lei 10.436/02: Brasília, DF: Senado, 2002.

. Decreto 5.626/05: Brasília, DF: Senado, 2005.

FERNANDES, S.; MOREIRA, L.C. Políticas de educação bilíngue para Surdos: o contexto brasileiro. In:

http://www.scielo.br/scielo.php?pid=S0104-

40602014000600005\&script=sci_arttext. Acesso em 13 de Dez de 2015 às 20:17h.

KUPFER, M.C.M. Problemas de aprendizagem ou estilos cognitivos? Um ponto de vista da Psicanálise. In: RUBISTEIN, E. (org.) Psicopedagogia: uma prática, diferentes estilos. São Paulo: Casa do Psicólogo, 1999, p. 65-78.

LACERDA, C.B.F, LODI, A.C.B. A inclusão escolar bilíngue de alunos Surdos: princípios, breve histórico e perspectivas. In: LACERDA, C.B.F, LODI, A.C.B. (org.) Uma escola, duas línguas: letramento em língua portuguesa e língua de sinais nas etapas iniciais de escolarização. Porto Alegre: Editora Mediação, 2010, p. 11-32.

PEREIRA, M. C. da C (Org.) LIBRAS. Conhecimentos além dos sinais. São Paulo: Pearson Prentice Hall, 2011.

Recebido em: 29/02/2016

Aceito em: 30/06/2016 